\title{
ENSINO DA LEITURA E DA ESCRITA: REFLEXÕES ACERCA DA FORMAÇÃO E DAS PRÁTICAS DOCENTES
}

\author{
Leandra Ines Seganfredo SANTOS \\ Universidade do Estado de Mato Grosso, Campus Sinop
}

RESUMO: Este trabalho objetiva refletir acerca da formação e das práticas de docentes de Língua Portuguesa, mestrandos do Programa em Rede de Mestrado Profissional em Letras (PROFLETRAS) da unidade da Universidade do Estado de Mato Grosso, Campus de Sinop. Os dados são provenientes das discussões e produções teórico-práticas desenvolvidas no decorrer da disciplina obrigatória "Aspectos Sociocognitivos e Metacognitivos da Leitura e da Escrita" em que foram propostas atividades de leitura e escrita. No que diz respeito ao trabalho com a leitura, pautou-se em estratégias de leitura (SOLÉ, 1998) mediante uso da técnica de protocolo de leitura (BORTONI-RICARDO et al, 2013, LEFFA, 1996). Já o trabalho de escrita foi realizado com elaboração e aplicação de sequências didáticas (DOLZ, NOVERRAZ e SCHNEUWLY, 2004) em que se enfatizou o trabalho de reescrita, observando-se, sobretudo, a importância do turno do professor na correção e feedback da produção textual (RUIZ, 2001). O corpus de análise deste estudo é o material descritivoanalítico resultante da produção final de cada mestrando que cursou a disciplina e objetiva-se (re)conhecer como eles se apropriam da teoria para desenvolver as propostas práticas em suas respectivas salas de aula. Os resultados mostram que as discussões teóricas e a realização das propostas empoderaram os docentes para a realização de uma prática diferenciada em sala de aula mediante apropriação de diferentes técnicas e estratégias de leitura, bem como do uso efetivo do procedimento metodológico sequência didática. Revelou também, a importância de se trabalhar a linguagem em uma perspectiva que considere os aspectos sociocognitivos, metacognitivos e culturais.

PALAVRAS-CHAVE: ensino de língua portuguesa; produção textual; protocolos de leitura.

ABSTRACT: The aim of this paper is to reflect about the training and practices of Portuguese Language teachers. These teachers are students in the Professional Master's Network Letters Program (PROFLETRAS), in the Mato Grosso State University, Campus of Sinop. Data was collected from the discussions and theoretical and practical productions developed during the subject "socio-cognitive and metacognitive aspects in reading and writing" with reading and writing activities. The reading work was guided through reading strategies (SOLÉ, 1998) by the use of reading protocol technique (BORTONI-RICARDO et al, 2010, LEFFA, 1996). The writing work was carried out with elaboration and implementation of didactic sequences (DOLZ, NOVERRAZ and SCHNEUWLY, 2004) in which the teachers emphasized the rewriting work, noting especially the importance of the teacher's turn in the correction and textual production feedback (RUIZ, 2001). The corpus of analysis is the resulting descriptive and analytical material resulted of the final production of each student. The purpose is to (re)know how they appropriate the theory to develop practical proposals in the classrooms. The results show that the theoretical discussions and the proposals empowered teachers to perform a different practice in the classroom through appropriation of different techniques and reading strategies, as well as the effective use of methodological didactic procedure. The results also showed the importance of study a language in a perspective that considers the socio-cognitive, metacognitive and cultural aspects.

KEYWORDS: Portuguese Language teaching; textual production; reading protocols.

\section{Introdução}


Dados atuais que retratam a formação docente e índices de leitura e escrita de alunos da Educação Básica (Rojo, 2009; Gatti, 2010; Ferrarezi Jr. e Carvalho, 2015, para citar apenas alguns) têm apontado para situações bastante desanimadoras e desafiadoras.

No que concerne à formação inicial de professores, estudos (ver, por exemplo, Abrucio, 2016, Gatti, 2008) mostram que os cursos de licenciatura não têm oferecido uma formação que capacite o profissional para uma atuação que atenda aos anseios da sociedade contemporânea, marcadamente caracterizada pela necessidade de alto domínio de letramentos. Algumas políticas públicas estão sendo desenvolvidas, no sentido de intervir na situação, como é o caso do Programa Interinstitucional de Bolsas de Iniciação à Docência (PIBID).

Já no que fiz respeito à formação continuada, o Programa de Mestrado Profissional Nacional em Rede - PROFLETRAS - aparece como uma possibilidade promissora de enfrentamento dessas questões, oferecendo a capacitação em nível stricto sensu a professores efetivos da rede pública de ensino.

Das 49 (quarenta e nove) unidades do Programa sediadas em diferentes instituições de ensino superior do Brasil, duas delas estão sediadas em dois campi da Universidade do Estado de Mato Grosso (UNEMAT), uma na cidade de Cáceres e outra na cidade de Sinop. Em Sinop, desde a implantação, em 2013, a unidade oferta dezoito vagas anuais. Caracterizada como formação continuada assistida (SANTOS e SANTOS, 2016), em um processo de pesquisa colaborativa (BORTONI-RICARDO, 2008), os docentes do quadro permanente do Programa, por meio de diferentes projetos institucionais, desenvolvem com seus orientandos, ao longo do curso, propostas de estudos interventivos visando intervir diretamente em um fenômeno/problema de sala de aula, relacionado à leitura e à escrita. Para tanto, implementase, também, ao longo do desenvolvimento das disciplinas requeridas para cumprimento de créditos, uma metodologia que contemple questões teórico-metodológicas. Em outras palavras, cada disciplina ofertada aborda diferentes teorias e, via de regra, propõe-se uma intervenção em sala de aula, relacionando o aporte teórico lido/discutido com os pares e a construção e implementação de uma proposta pedagógica.

Na disciplina Aspectos Sociocognitivos e Matacognitivos da Leitura e da Escrita (ASMLE), disciplina obrigatória da Matriz Curricular do Programa, a ementa sugere o seguinte:

Estudo de processos sociocognitivos relacionados à aquisição da linguagem e ao aprendizado e desenvolvimento da leitura e da escrita. Reflexão sobre a articulação entre as abordagens cognitivas da leitura e da escrita e as pesquisas sobre letramento. Elaboração de didáticas para o ensino de Língua Portuguesa com base na construção sociocognitiva do significado relacionada ao trato com textos orais e escritos. (MATRIZ PROFLETRAS, 2013, p. 8).

Para desenvolver a ementa, o grupo de docentes atuantes nesta disciplina, nas instituições espalhadas pelo Brasil, elegeram conteúdos a serem abordados em unidade básica e unidade transversal. Na primeira, propõem-se a discussão de conteúdos como: conceitos de cognição, metacognição e aprendizagem; a metacognição em leitura e escrita; modelos e estratégias de construção do significado em leitura e escrita; contribuições das neurociências para a compreensão da aprendizagem e das dificuldades de aprendizagem na leitura e na escrita; processos cognitivos implicados na leitura e na escrita, como a atenção, a emoção, o conhecimento prévio e a intersubjetividade; letramento crítico, desnaturalização de visões de mundo e de construção compartilhada da realidade; e, construção sociocognitiva do significado e os textos orais e escritos. $\mathrm{Na}$ segunda, como o próprio nome sugere, transversalmente, apresentam-se, discutem-se, elaboram-se e executam-se metodologias de ensino do texto: automonitoramento, práticas de análise linguística, de correção, de revisão, 
de refacção do texto do aluno, projetos de letramento, sequências didáticas, protocolos de leitura, dentre outras.

No que diz respeito ao trabalho desenvolvido na unidade PROFLETRAS/Sinop, descreve-se como objetivo da disciplina (re)leituras e discussões de textos que abordam a leitura e a escrita nos seus aspectos sociocognitivos e metacognitivos, possibilitando ao professor-mestrando a reflexão e a operacionalização quanto ao seu ensino, tomadas como práticas efetivas, e quanto à formação de leitores e escritores proativos para o exercício da cidadania em uma sociedade letrada. Ademais, encoraja-se a proposição de atividades interventivas, descrição e análise dos resultados obtidos, em significativo exercício de integração teoria e prática, em contexto real de intervenção em determinada prática escolar.

\section{Da formação do docente de línguas: a disciplina Língua Portuguesa em questão}

Um estudo coordenado por Abrucio (2016) mostra que os cursos de licenciaturas, geralmente, têm se preocupado mais com "o que ensinar" do que com o "como ensinar". O fato da didática ocupar um lugar secundário nas matrizes curriculares dos cursos de graduação faz com que as metodologias de ensino também fiquem em segundo plano. Para ele "hoje, predomina nas IES uma formação com poucas disciplinas metodológicas, desarticuladas do restante da grade curricular, inclusive em relação àquelas que estariam mais próximas do campo teórico da área pedagógica” (ABRUCIO, 2016, p. 42). Dentre os principais problemas na formação docente, o estudo revelou questões importantes, como, por exemplo, a necessidade de integração do tripé formativo (universidades-centros formadores/redes de ensino/escolas); o perfil do aluno-futuro-professor, que, via de regra, é de famílias de nível socioeconômico menor, caracterizando-se como trabalhador diurno e estudante noturno; a fragilidade do currículo da Educação Básica marcado por um ensino conteudista e disciplinar;

a falta de uma profissionalização da prática docente, da formação inicial à continuada, que realmente atenda às necessidades formativas e às especificidades de cada contexto; e, por fim,

a urgente necessidade de criação de mecanismos de valorização, atratividade e motivação para a carreira docente, que passa por questôes salariais, formativas, estruturais, dentre outras.

Bolzan e Isaia (2010, p. 23, grifos no original) sugerem uma formação na perspectiva do que denominaram pedagogia universitária, ou seja, "um espaço em movimento, no qual podemos analisar e compreender os fenômenos de aprender e de ensinar as profissões, sobretudo, um espaço no qual a própria docência universitária em ação pode ser revisitada e constantemente reconstruída". Para elas, tal pedagogia caracteriza-se em processos formativos, cujo conceito basilar fundamenta-se no conhecimento compartilhado que envolve as noções de aprendizagem colaborativa. Tal processo, explicam as autoras, "envolve um sistema organizado no qual participam tanto os sujeitos que se preparam para suas profissões quanto aqueles que já estão engajados na docência” (p. 19).

No que concerne às instâncias governamentais, referindo-se à formação docente, em meados de 2015 foram publicadas, pelo Conselho Nacional de Educação (Resolução № 2, de $1^{\circ}$ de julho de 2015) ${ }^{1}$, as Diretrizes Curriculares Nacionais para a formação inicial em nível superior e para a formação continuada. O referido documento destaca os seguintes princípios norteadores da base comum nacional para a formação inicial e continuada: "a) sólida formação teórica e interdisciplinar; b) unidade teoria-prática; c) trabalho coletivo e interdisciplinar; d) compromisso social e valorização do profissional da educação; e) gestão democrática; f) avaliação e regulação dos cursos de formação" (BRASIL, 2015, p. 2).

\footnotetext{
1 Disponível em: http://portal.mec.gov.br/escola-de-gestores-da-educacao-basica/323-secretarias112877938/orgaos-vinculados-82187207/21028-resolucoes-do-conselho-pleno-2015, acesso em 20 de outubro de 2016
} 
De forma geral, evidencia-se no documento uma necessidade eminente de formação articulada à educação básica. Fica evidente o anseio por uma formação que capacite os docentes para atuação em suas áreas de conhecimento, entretanto, aptos para o desenvolvimento de um trabalho interdisciplinar. Neste sentido, no artigo segundo, parágrafos primeiro e segundo, por exemplo, lê-se que a docência é compreendida "como ação educativa e como processo pedagógico intencional e metódico, envolvendo conhecimentos específicos, interdisciplinares e pedagógicos [...]" e que a prática "profissional do magistério da educação básica é permeada por dimensões técnicas, políticas, éticas e estéticas por meio de sólida formação, envolvendo o domínio e manejo de conteúdos e metodologias, diversas linguagens, tecnologias e inovações, contribuindo para ampliar a visão e a atuação desse profissional" (BRASIL, 2015, p. 3).

Pode-se dizer que as diretrizes apontam para uma forte tendência de formação cujos princípios pressupõem a articulação entre a teoria e a prática, em uma perspectiva interdisciplinar, dando significado e relevância aos conhecimentos e vivência da realidade social e cultural, fundada no domínio dos conhecimentos científicos e didáticos, contemplando a indissociabilidade entre ensino, pesquisa e extensão. Elas também reconhecem as instituições de educação básica como espaços necessários à formação dos profissionais do magistério. A educação precisa ser vista, conforme alerta o documento, como processo emancipatório e permanente. Também salientam para a necessidade de promover espaços para a reflexão crítica sobre as diferentes linguagens e seus processos de construção, disseminação e uso, incorporando-os ao processo pedagógico.

O Art. $8^{\circ}$ descreve que se espera que o egresso de cursos de formação inicial em nível superior esteja apto, a trabalhar na promoção da aprendizagem e do desenvolvimento de sujeitos em diferentes fases do desenvolvimento humano, a dominar os conteúdos específicos e pedagógicos e as abordagens teórico-metodológicas do seu ensino, ter domínio das tecnologias de informação e comunicação, promover relações de cooperação, ter postura investigativa, integrativa e propositiva, demonstrar consciência da diversidade, entre outros tantos requisitos (BRASIL, 2015, p. 7-8).

O Art. $16^{\circ}$, por sua vez, revela que a formação continuada, em suas distintas modalidades - sendo a em nível de mestrado em questão neste texto uma delas - precisa levar em conta:

I - os sistemas e as redes de ensino, o projeto pedagógico das instituições de educação básica, bem como os problemas e os desafios da escola e do contexto onde ela está inserida;

II - a necessidade de acompanhar a inovação e o desenvolvimento associados ao conhecimento, à ciência e à tecnologia;

III - o respeito ao protagonismo do professor e a um espaço-tempo que lhe permita refletir criticamente e aperfeiçoar sua prática;

IV - o diálogo e a parceria com atores e instituições competentes, capazes de contribuir para alavancar novos patamares de qualidade ao complexo trabalho de gestão da sala de aula e da instituição educativa. (BRASIL, 2015, p. 14).

De maneira não desvinculada aos pressupostos descritos nas Diretrizes, estudiosos diretamente ligados à área da linguagem têm buscado compreender os processos formativos em nível de formação inicial e continuada do docente de línguas (ver, por exemplo, Silva et all, 2015; Freitas, 2016; Sartori, 2016).

Siqueira (2012, p. 48), por exemplo, afirma que, por lidarmos com a linguagem - um objeto tão complexo e maravilhoso, "apesar do desprestígio historicamente atribuído à nossa profissão ao longo de tantos anos, somos sim um grupo sofisticado e especializado de profissionais". Ele aponta que o profissional de Letras contemporâneo não é um generalista, e sua formação não pode se de ordem conteudística, mas sim, ligada à criticidade à autonomia e à reflexão. 
Seguindo na mesma direção, e corroborando as ideias descritas nas Diretrizes, Celani (2016, p. 548) assevera que

as teorias existem para serem transformadas em prática, na sala de aula, por exemplo. O que interessa para que haja aprendizagem é a transformação de uma determinada teoria em procedimentos de sala de aula que mantenham os alunos, no caso da escola pública, interessados e percebendo a relevância do que acontece na sala de aula. As teorias são necessárias nos cursos de formação, inicial e continua, mas deve haver sempre a transposição para a realidade da sala de aula.

Ademais, para a referida autora, é preciso se trabalhar saberes globais e saberes locais, ou seja, o "glocal" (KUMARAVADIVELU, 2006, citado em CELANI, 2016).

Tais questões, obviamente, afetam diretamente o ensino de Língua Portuguesa, tida como a principal disciplina no currículo responsável pelo ensino da leitura e da escrita. Com relação aos objetivos de ensino de Língua Portuguesa relacionados aos conteúdos previstos, os Parâmetros Curriculares Nacionais (BRASIL, 1998) pontuam que cabe à instituição escolar e, consequentemente, aos professores organizarem um conjunto de atividades que possibilitem ao aluno desenvolver o domínio da expressão oral e escrita em situações de uso público da linguagem, levando em conta as condições de produção, como lugar social do locutor em relação ao(s) interlocutor(res), finalidade ou intenção do autor, tempo e lugar material da produção e do suporte, dentre outras. Tais atividades precisam estar pautadas na seleção de gêneros a serem utilizados em situações de ensino segundo a concepção de linguagem como forma de interação.

$\mathrm{Na}$ sequência, discuto algumas questões acerca do tema, abordando uma de muitas possíveis perspectivas em que pode ser abordado, a saber, a perspectiva (meta)cognitiva.

\subsection{Do ensino da leitura e da escrita: processos cognitivos e metacognitivos}

Ensinar a escrever, assim como ensinar a ler, não é um processo simples. Demanda um engajamento entre o professor, os alunos, a escola e o meio. Enfim, trata-se de um macroprocesso. Tanto o processo de ensino de leitura e o processo de produção textual são diretamente afetados pelas escolhas teórico-metodológicas feitas pelo professor e pela unidade de ensino em que estão inseridos.

$\mathrm{O}$ (in)sucesso no desenvolvimento da leitura e da escrita pode ser atribuído, em grande medida, aos processos cognitivos e metacognitivos. Davis, Nunes e Nunes (2005) apontam que quando o aluno entra na escola passa por um processo de enculturação ${ }^{2}$ que o fará sair diferente de como entrou. Para eles, "o cidadão capaz de tomar decisões adequadas precisa dispor de: informações pertinentes a respeito do meio físico e social, de si mesmo e dos outros; estratégias de pensamento que lhe permitam operar sobre essas informações; valores que orientem a sua ação" (DAVIS, NUNES e NUNES, 2005, p. 207).

Com base em Flavell (1976), Davis, Nunes e Nunes (2005) e Jou e Sperb (2006) conceituam metacognição como a capacidade do ser humano de monitorar e auto-regular os processos cognitivos; refere-se, pois, à regulação e orquestração desses processos em relação aos objetos cognitivos ou dados sobre os quais eles incidem, usualmente a serviço de alguma meta ou objetivo concreto. Jou e Sperb (2006, p. 212) pontuam que por meio da metacognição os indivíduos podem:

\footnotetext{
2 Os autores definem enculturação como "processo de apropriação de uma cultura, que se dá por meio de exposição a modelos aceitos (via imitação), explicações, interações e feedbacks que forneçam informações úteis para a aprendizagem em curso" (DAVIS, NUNES e NUNES, 2005, p. 207).
} 
construir conhecimentos e habilidades que tenham maior possibilidade de sucesso e de transferência; aprender estratégias de solução de problemas que sejam passíveis de serem auto-reguladas; adquirir autonomia na gestão das tarefas e nas aprendizagens, auto-regulando-se e se auto-ajudando; construir uma auto-imagem de aprendiz produtivo e, com isso, obter motivação para aprender.

Em estudo realizado, Leffa (1996) chega a algumas conclusões, ao: afirmar que a atividade metacognitiva caracteriza-se como resultado do desenvolvimento; estabelecer a correlação entre metacognição e proficiência em leitura, isto é, quanto mais intenso for o hábito de leitura do sujeito, maior será a sua capacidade para avaliar a sua própria compreensão e, consequentemente, para utilizar estratégias de leitura mais adequadas; inferir que a instrução influencia o desenvolvimento metacognitivo, isto é, quando a criança é exposta a um programa sistemático de monitoramento de leitura compreensiva, sua habilidade de leitura melhora; e, expor que a importância do objetivo do leitor é que determinará a eficácia de uma determinada estratégia de leitura.

Destarte, a metacognição caracteriza-se como importante perspectiva no âmbito educacional e no trabalho de ensino da leitura e da escrita.

Consoante à leitura, muitos conceitos lhes são atribuídos. Neste estudo, a despeito dos pressupostos adotados na disciplina ASMLE, compreendo leitura, conforme definição de Leffa $(1996,1999)$ para quem a leitura é um processo feito de múltiplos processos, que ocorrem tanto simultânea como sequencialmente. A leitura é vista, então, pelo autor, como um processo de interação social, em que para que se compreenda o ato de ler, há de se considerar tanto o papel do leitor, quanto do texto e o processo de interação entre o leitor e o texto. Neste sentido, Leffa pondera que o leitor precisa ter não só competências fundamentais para o ato da leitura, mas também, intenção de ler - característica exclusiva do ser humano.

A linguística cognitiva traz a motivação como um conceito relevante. Palomanes e Bravin (2012, p. 42) definem que o termo motivação é usado para

se referir às diversas maneiras como as variadas construções linguísticas podem ser criadas em função de necessidades pragmáticas, para sinalizar que as construções podem ser sistematicamente relacionadas umas às outras e para explicar como uma correspondência forma-significado pode se estabelecer numa língua.

Várias técnicas, procedimentos e estratégias podem ser usadas na perspectiva (meta)cognitiva de ensino de leitura, como, por exemplo, propostas de leitura tutorial (BORTONI-RICARDO, 2010, BORTONI-RICARDO, MACHADO e CASTANHEIRA, 2013) por meio do instrumento de protocolo de leitura, da técnica cloze (LEFFA, 1996), bem como estratégias de leitura propostas por Solé (1998) de como se pode desenvolver o antes, o durante e o depois do processo de leitura.

A análise de protocolo de leitura envolve uma espécie de entrevista em que o pesquisador/professor desenvolve perguntas indiretas na tentativa de obter dados sobre os processos usados pelo leitor, descrevendo, assim, as estratégias de leitura que estão sendo utilizadas no processo. Para Leffa (1996, p. 54), "a técnica da entrevista, ao permitir que o investigador avalie a consciência que o leitor tem de suas próprias estratégias, torna também possível avaliar a correlação entre o comportamento metacognitivo do leitor e sua compreensão de leitura”. Ao analisar o protocolo o professor pode encontrar subsídios para aprimorar o processo de ensino que vem desenvolvendo.

Para além do trabalho de leitura, cabe ao professor, sobretudo ao alfabetizador (nos anos iniciais da educação básica) e ao de Língua Portuguesa (anos finais), o trabalho de ensino da escrita/produção textual, em que a perspectiva (meta)cognitiva também pode em muito contribuir. 
$\mathrm{Na}$ década de oitenta do século passado, por exemplo, Hayes e Flowers (1980) descreveram a técnica de análise de protocolos de escrita e como a descrição pode auxiliar no processo. Apesar de termos entrado em contato com a técnica, em discussão com os mestrandos, optamos por utilizar a técnica de protocolos de leitura para os trabalhos que enfatizariam a leitura e, para o trabalho com a escrita, optamos por destacar processos de correção, com base em Ruiz (2015), na tentativa de desmitificar que o aluno precisa escrever para o professor e este lhe emitir uma nota.

A discussão acerca da escrita iniciou com a apreciação de um modelo de produção de textos proposto por Meurer (1997) e a questão da limitação de modelos. Abordou-se acerca do procedimento metodológico de sequência didática proposta por Dolz, Noverraz e Schneuwly e como o uso de tal procedimento pode contribuir para o desenvolvimento, não só da escrita, bem como da oralidade e da leitura.

A sequência didática é caracterizada por um "conjunto de atividades escolares organizadas, de maneira sistemática, em torno de um gênero textual oral ou escrito" (DOLZ, NOVERRAZ e SCHNEUWLY, 2004, p. 97). O esquema proposto pelos autores envolve apresentação da situação, produção inicial, módulos e produção final.

Partiu-se, então, para a discussão da escrita como um processo de produção textual, na perspectiva de usos social da língua escrita, ou seja, do letramento, e do professor como um agente de letramento (KLEIMAN, 2006; 2007; BORTONI-RICARDO, MACHADO e CASTANHEIRA, 2013).

A escrita tem sido descrita como o conjunto de habilidades linguísticas e psicológicas, como a habilidade de registrar unidades de som até a capacidade de transmitir ideias ao leitor pretendido. É um processo de expressar ideias e organizar pensamentos em linguagem escrita. Tal processo, entretanto, não é natural, já que os usos da linguagem não são neutros em referência às relações de poder na sociedade, o que pode contribuir para a desigualdade e a exclusão (ROJO, 2009). Neste sentido, para poder ler e escrever, o aluno precisa reconhecer e usar componentes relativos ao domínio do código, como a segmentação em palavras e frases, as correspondências regulares de som-letra, as regras ortográficas, o uso de maiúsculas, assim como componentes relativos ao domínio textual, tais como o conjunto de recursos coesivos de conexão, de relação temporal, de relação causal (KLEIMAN, 2007).

Ferrarezi Jr. e Carvalho (2015, p. 19) pontuam que "a escrita é um ato artificial, uma tecnologia e, como tal, permite-lhe ser aprendida, desde que corretamente trabalhada em sala" e isso requer tempo e dedicação por parte do professor e dos alunos. Neste sentido, a produção textual acaba sendo um ir e vir ao texto, ou seja, uma revisitação com novos olhares e novas reflexões. Portanto, a proposta de Ruiz (2015) é de que o professor realize formas interventivas e oportunize ao aluno tal revisitação. Para esta autora, uma forma de intervenção é a propositura da correção textual-interativa, por caracterizar-se altamente polifônica, expressão máxima da dialogia, consoante Bakhtin (1992). Isso também oportuniza, em certa medida, a ativação de processos de (meta)cognição.

No tópico vindouro, discorro acerca das práticas desenvolvidas como uma possibilidade de interlocução na perspectiva descrita nesta seção.

\section{Das práticas docentes: diálogos teórico-metodológico-reflexivos}

Para o recorte deste texto, apresento e discuto dez intervenções elaboradas e desenvolvidas por mestrandos que cursaram a disciplina ASMLE em 2015/02. Para melhor apresentação dos dados optei por separá-los em dois grupos: o primeiro aborda, especificamente, o trabalho com a leitura; o segundo, por sua vez, evidencia ações de escrita e reescrita.

\subsection{Protocolos de leitura: experienciando diferentes estratégias de leitura}


O grupo dos cinco trabalhos desenvolvidos pelos mestrandos com foco no desenvolvimento da leitura utilizou a análise de protocolo como estratégia de leitura para desenvolvimento da proposta (LEFFA, 1996; BORTONI-RICARDO, 2013). Vale mencionar aqui que nenhum deles havia utilizado essa metodologia em sala de aula anteriormente, caracterizando-se já, uma inovação para eles, o que, apesar de discutirmos os textos base durante as aulas no mestrado, o momento de prática proposto seria inédito, o que lhes causava certa ansiedade e insegurança quanto aos resultados.

O primeiro trabalho buscou discutir a leitura em uma perspectiva crítico-interacionista, refletindo sobre os papeis sociais do professor e do aluno no processo de aquisição da leitura. Para tanto, M1 selecionou cinco de trinta e oito alunos de um $5^{\circ}$ ano de uma escola municipal localizada no Pará. A seleção aconteceu sob a orientação da professora regente da sala e visou a participação daqueles que pouco se envolviam nas atividades de leitura e escrita desenvolvidas em suas aulas e por possuírem pouco interesse e quase nenhuma habilidade leitora. Atentando ao aporte teórico abordado durante as aulas no mestrado, o texto escolhido por M1 para a realização da proposta foi um conto regional, local e com temática voltada ao folclore da cidade, que tem como traço comum a fala do cotidiano, pois acreditava que seria uma maneira de torná-los mais próximos da significação do leitor, visando desenvolver principalmente seu processo sociocognitivo. Somente posteriormente usou a técnica da leitura dialogada, feita em voz alta, com pausas frequentes, uma maneira prática de envolver o aluno no que estava sendo lido.

M1 afirmou que seu primeiro objetivo foi desestabilizar a ideia que os alunos apresentaram de que leitura é uma atividade chata e cansativa. Ela reiterou que ao envolvê-los no processo de significação de leitura, os conduziu "rumo à autonomia, levando-os a observar a leitura, interferir, fazer inferências, relacionando os fatos lidos ao seu conhecimento de mundo e por último proporcionar a sua progressão, através dos questionamentos que surgiam" (M1, 2015, p. 17). Outro ponto salientado por M1 foi acerca da importância do papel do professor como mediador e interventor no processo de leitura, no sentido de criar situações que oportunizem o diálogo e a construção de significados.

Assim M1 reflete acerca da atividade desenvolvida:

O mais importante de tudo no desenvolvimento do protocolo foi perceber como eles participaram de cada uma das etapas, de tal maneira que não precisei enchê-los de questionários à parte do texto, porque exploramos juntos e depois individualmente todas as suas possibilidades, sem negligenciar nenhum de seus detalhes importantes e sem deixar que as hipóteses que foram levantadas fossem devidamente exploradas (M1, 2015, p. 17)

O segundo trabalho foi um protocolo através da mediação com leitura tutorial, foi desenvolvido por M2 com duas alunas de um $6^{\circ}$ ano que têm históricos distintos no que tange ao contato com leitura, particularmente em seu universo familiar e social. Uma semana antes de realizar o protocolo, M2 orientou as alunas a buscarem um livro na biblioteca e o lerem individualmente. Com a realização dos protocolos, M2 deu-se conta de como cada aluno precisa ser estimulado de maneira diferenciada para avançar na apropriação da leitura, quanto aos elementos explícitos e implícitos do texto, bem como quanto à compreensão lexical.

A realização da atividade também oportunizou M2 identificar dificuldades durante o próprio protocolo, desafiando-a a criar novas estratégias para saná-las. Ela evidenciou ainda que um conhecimento de mundo reduzido dos leitores lhes restringe a compreensão do que está sendo lido, requerendo do professor lançar mão de diferentes estímulos para ampliar-lhes o repertório. Para M2, os resultados obtidos permitiram um diagnóstico, embora restrito, no sentido de detectar alguns fatores que impedem o desenvolvimento do gosto pela leitura. As respostas dadas pelas alunas aos questionamentos feitos, levam a crer, em menor ou maior 
grau de dificuldades, que estas têm dificuldades em decodificar o texto, o que demonstra que houve uma lacuna no que tange as orientações acerca de leitura.

M2 convida os professores para rever a conduta em sala de aula e assumir as responsabilidades, enquanto professores de língua portuguesa e literatura. Para ela, é imprescindível "desenvolver nos nossos alunos as competências da boa leitura, preparar aulas que de fato sanem as dificuldades na compreensão do texto escrito e amplie o universo de conhecimento de nossos alunos, não há mais espaço para o despreparo, para o improviso" (M2, 2015, p. 9). Convidada a refletir sobre sua prática, M2 pondera que:

a leitura tutorial é fundamental, para detectar as dificuldades dos alunos, bem como para a compreensão do processo utilizado e a necessidade de intervenções e elaboração de estratégias que levem a um melhor aproveitamento e compreensão da leitura por parte do aluno, o estímulo deve ser dado pelo professor nos momentos de leitura compartilhada, na análise da obra feita através do modelo tutorial, através do qual serão identificadas as necessidades de novas metodologias ou simplesmente o reforço das que o aluno já utiliza. (M2, 2015, p. 1)

Por semelhante modo, após desenvolver a intervenção com duas alunas, com diferentes níveis de desenvolvimento da leitura (uma mais desenvolvida e outra que apresentava mais dificuldades), M3 aponta a importância da leitura tutorial para o ensino de estratégias de leitura, pois, segundo ele, "através do protocolo de leitura e da mediação, o professor pode identificar quais estratégias os alunos utilizam, quais precisam ser reforçadas e quais precisam ser ensinadas, sendo a leitura compartilhada um ótimo meio para que isso ocorra" (M3, 2015, p. 1).

Primeiramente, interessou-lhe verificar quais as estratégias de leitura eram utilizadas por elas, bem como reforçar essas estratégias e, através da mediação, apresentar outras. Com base em Bortoni-Ricardo; Machado; Castanheira (2015), M3 usou uma metodologia com encontros individuais para aplicação de protocolo verbal autorrevelação, por ser executado durante a realização da leitura e por permitir o trabalho pedagógico de andaimagem.

Em suas análises, M3 concluiu que as alunas usaram estratégias de leituras parecidas na obtenção de informações, localizando as explícitas e inferindo as implícitas; elas também fizeram correlações com suas experiências de vida, afirmou M3, em que houve necessidade, em vários momentos, de sua mediação por meio de questionamentos para estimular o raciocínio e a compreensão. No desenvolvimento da atividade, M3 evidenciou que os maiores problemas encontrados relacionaram-se "às questões de decodificação, vocabulário e pontuação que impediram a fluência e uma melhor compreensão da leitura" (M3, 2015, p. $15)$.

M4 também optou por realizar a atividade proposta durante a disciplina ASMLE com dois alunos do $8^{\circ}$ ano que apresentavam processos de aprendizagem distintos, uma menina com defasagem idade-série, muito retraída, que não desenvolvia as atividades propostas em sala de aula e nunca tinha feito leitura oralizada; e um aluno bastante extrovertido, que demonstrava maior facilidade de compreensão de leitura de sua turma. Para tanto, M4 selecionou um texto de um livro didático.

Assim como aconteceu com os demais colegas que se aventuraram pelos caminhos da experimentação de novas metodologias, no caso, o desenvolvimento da leitura por meio de protocolos, na apresentação e análise realizadas por M4, fica evidente, certa insegurança para a realização da atividade proposta. Entretanto, chama-nos a atenção, todo o processo de elaboração e aplicação da proposta, desvelando o olhar de professor-pesquisador-reflexivo. Em seu trabalho final, M4, por exemplo, faz questão de registrar suas inseguranças, escolhas e resultados, para mostrar ao leitor um amadurecimento, uma vez que, ao relatar as ações desenvolvidas, ao mesmo tempo reflete e aponta como fará em situações futuras. O excerto 
que segue retrata o processo de reflexão desencadeado pela mestranda, em que relaciona a teoria estada em sala e a prática utilizada com o aluno:

Um equívoco cometido por mim, não foi ter esclarecido ao aluno que suas previsões seriam confirmadas ou não depois pela leitura, que não tinham que estar certas, mas que eram apenas previsões. Isso talvez teria lhe deixado mais seguro, já que em algumas de suas respostas eram perguntas, nas quais ele demonstrava insegurança e solicitava uma confirmação. Também deveria ter estabelecido um objetivo para a leitura, o que poderia instaurar um elo entre o texto e os alunos, conforme diz Solé (1998). (M4, 2015, p. 10).

Já na realização do segundo protocolo, M4 registra: “eu não me esqueci de observar em voz alta que se tratava de previsões, que poderiam ser confirmadas ou não durante a leitura" (M4, 2015, p. 13). E ainda, acerca de uma inferência feita pela aluna, M4 pondera: "Eu, como professora, não soube intervir adequadamente para que ela compreendesse que se referia ao ambiente, porém com a releitura feita por mim do trecho do texto e do significado da palavra anárquico, ela inferiu que não se tratava de uma pessoa...” (M4, 2015, p. 14).

A proposta desenvolvida por M4 retrata todo seu cuidado no antes, durante e depois da leitura (BORTONI-RICARDO, MACHADO e CASTANHEIRA, 2013). Convidada a refletir sobre a realização do trabalho, M4 assim relata:

Então, a forma como foi realizado este trabalho se mostrou válida mas limitada, uma vez que os alunos se mostraram responsáveis, participativos, mais autônomos, concentrados e dispostos a aprender, porém esta condição de estarem presentes apenas o professor e um aluno foge à realidade cotidiana. O ambiente coletivo da sala de aula em escolas públicas, na maioria das vezes, não propicia condições de diálogo entre professor e alunos, devido aos problemas de indisciplina, já que a maior parte dos alunos, pegando o viés da burocratização escolar, acredita que somente são válidas as atividades "no caderno", pois estas ficam registradas. Também, nos anos finais do Ensino Fundamental, temos a separação das aulas em disciplinas, o que muitas vezes reduz os momentos com os alunos a, no máximo, quatro horas semanais, o que se torna pouco para um trabalho significativo no momento em que os alunos estão aprendendo a melhorar as capacidades cognitivas por meio das capacidades metacognitivas. (M4, 2015, p. 19)

M4 assevera, ainda, a necessidade eminente de o professor ter uma melhor formação teórica sobre a leitura e os processos cognitivos, metacognitivos e sociocognitivos que a envolve. Ela também orienta para "um trabalho mais coeso e contínuo sobre esta entre as diversas disciplinas escolares e ainda, assumirmos que a leitura é um conteúdo procedimental que precisa ser aprendido na escola, durante todo o processo de escolarização do aluno". Por fim, menciona isso será possível com a criação de momentos para atendimento individualizado a grupos menores.

O último trabalho com protocolo de leitura aqui retratado difere-se substancialmente das demais experiências anteriormente descritas, pelo fato de ter sido realizado com uma criança não alfabetizada (seis anos), a partir de um texto imagético para ser lido por ela e outro escrito, lido pela mestranda. Já durante o desenvolvimento da disciplina ASMLE, todos os mestrandos mostraram-se curiosos quanto aos possíveis resultados que uma proposta nessa perspectiva resultaria, sobretudo por se tratarem de sujeitos com formação inicial em Letras e não em Pedagogia, o que, teoricamente, impõem-lhes restrições quanto ao trabalho pedagógico com crianças menores.

A seleção do sujeito para o desenvolvimento da proposta aconteceu, consoante M5, pelo fato de "sempre ler numa 'língua' inventada, leu, por exemplo, 'thurel mefai fou arrouli' 
para "A bola bateu na trave"”. De acordo com M5, seu objetivo era investigar as estratégias que a criança não alfabetizada utilizaria durante o procedimento de leitura, "descobrindo como as reflexões feitas contribuem para o avanço no processo de alfabetização e de que maneira o protocolo de leitura pode contribuir com o ensino e a aprendizagem da leitura" (M5, 2015, p. 1) e para tanto selecionou duas obras do acervo da classe do aluno.

O protocolo desenvolvido a partir do texto imagético apontou a importância da mediação do professor, oferecendo-lhe andaimes (BORTONI-RICARDO, 2013), para que a crianças se aproprie do conhecimento que já possui da escrita alfabética como uma estratégia para a decodificação das palavras, fazendo uso, dessa forma, da consciência metalinguística na medida em que reflete sobre a língua. No que diz respeito à língua escrita, M5 também observou que o aluno fez uso de estratégias de compreensão do código nas quais se apoia para tentar decodificar o que está escrito. Assim M5 conclui acerca da intervenção que realizou:

o uso de protocolos de leitura pode ser um importante instrumento tanto na diagnose do nível de leitura e do estágio de alfabetização no qual a criança se encontra, quanto no próprio processo de alfabetização no qual está inserida. (M5, 2015, p. 1)

Um olhar holístico para as cinco intervenções, permite-nos afirmar que a seleção dos sujeitos, via de regra, pautou-se por aqueles com mais dificuldades em leitura. Os resultados, por sua vez, mostram que diferentes estratégias de leitura, oportunizadas aos alunos, possibilitam avanços consideráveis no processo de aquisição da leitura e compreensão de textos. Outra questão bastante evidente foi a importância de o professor criar e mediar situações de aprendizagem que levem os aprendizes a refletir, questionar e criar hipóteses sobre a leitura e sobre o código escrito, para que possam avançar no processo que caracterizase por um continuum.

Os mestrandos empoderaram-se desse conhecimento, entretanto, também evidenciaram que esse tipo de atividade fica difícil de ser desenvolvida em salas com muitos alunos onde a heterogeneidade, em todos os sentidos, dá a tônica do espaço, já que requer muito tempo e dedicação ao aluno.

\subsection{Escrita e reescrita: o importante papel do professor como mediador}

Cinco trabalhos foram desenvolvidos pelos mestrandos na perspectiva de escrita e reescrita.

M6 preocupou-se em desenvolver uma proposta de ensino de LP que revelasse a importância de se tomar o texto como objeto central das atividades a desenvolver nas aulas. Para além de sua própria postura reflexiva sobre a língua, desafiou os alunos a também refletirem a partir de situações concretas de produção textual. Foi foco de sua intervenção um olhar criterioso a sua própria ação enquanto mediadora, papel que lhe compete como importante recurso rumo à produção de textos mais bem elaborados. Por fim, apropriou-se de diferentes estratégias de correção no sentido de evidenciar aquelas mais adequadas a serem adotadas.

Para este estudo, a referida mestranda selecionou uma turma de $7^{\text {a }}$ série de uma escola de contexto privado de ensino. O corpus é composto por 30 textos narrativos produzidos pelos alunos em cada um de dois momentos propostos (escrita e reescrita após a correção). Os textos reelaborados foram corrigidos novamente e devolvidos aos alunos. Para a análise, M6 selecionou textos de dois alunos, com o seguinte objetivo:

observar como os alunos lidaram com as orientações que receberam na primeira correção e se serviram para melhorar o texto ou não na produção da segunda versão. Os dois textos selecionados são representativos de duas posturas diferentes frente ao recomendado nas correções. (M6, 2015, p. 11) 
O processo de correção adotado pela mestranda envolveu o emprego de correção indicativa, classificatória e textual-interativa, sugeridas pela pesquisadora Eliana Ruiz (2015), que foram apresentadas e discutidas por ela mesma em oficina desenvolvida no decorrer da disciplina ASMLE. O texto de M6 evidencia que ela não só se apropriou da teoria estudada, bem como a colocou em prática em um de seus contextos de trabalho. Isso lhe permitiu evidenciar na prática como a teoria se materializa. Ela ressaltou, também, que alguns alunos "se atentaram às solicitações de correção apresentadas à primeira versão, mas houve aqueles que foram negligentes para com essas recomendações quando da escrita da segunda versão, demonstrando pouca disposição para a tarefa de refacção". (M6, 2015, p. 13). Ao refletir sobre este fato, M6 pondera que isso pode ser decorrência de uma prática equivocada em que professores têm condicionado os alunos a entenderem a produção textual como produto e não como processo.

Para ela, atividades desta natureza permitem ao aluno refletir sobre a língua, o que podem torná-los melhores leitores e escritores. Interessante se observar as conclusões a que M6 chega, após realizar a intervenção e refletir sobre suas ações:

As atividades de produção de texto, muitas vezes, ainda são concebidas como uma mera tarefa escolar para a qual o leitor em mente é apenas o professor. Desta forma, as atividades de escrita são concebidas como exercícios de redação, que devem atender a um conjunto de características expressos em sintonia com as normas gramaticais; o professor lê, marca os "erros", manda corrigir (nem sempre confere se isso aconteceu ou não) e parte-se para nova atividade. Não ocorre mediação e nem reflexão sobre a escrita, não se adotando, portanto, estratégias que colaborem efetivamente para o aperfeiçoamento da escrita do aluno. (M6, 2015, p. 15)

Fica evidente, nos dizeres de M6, que cabe ao professor, por meio da mediação, criar andaimagem (BORTONI-RICARDO, 2013) em uma perspectiva reflexiva do uso da língua. Assim M6 orienta:

O texto do aluno deve ser lido com seriedade e comprometimento pelo professor, de modo a enxergar nele também virtudes; não apenas defeitos. Compete-lhe empregar estratégias de correção que contribuam para o aluno se orientar na tarefa de refacção ou reelaboração de seu texto. (M6, 2015, p. 15)

Concluindo suas ponderações, M6 aponta duas questões: o fato de alguns alunos mostrarem-se reticentes ao trabalho de refacção, mantendo a concepção de que o primeiro texto escrito trata-se da produção final, ou seja, produto concluído e imutável. Ainda assim, ela aponta os resultados satisfatórios obtidos com aqueles que se dispuseram a realizar as reescritas sugeridas por ela.

Essa intervenção realizada por M6 mostra-nos pontos nevrálgicos no que diz respeito à escrita. Percebe-se que mesmo com o advento de novas teorias e reflexões, como as que discutem os gêneros textuais e os multiletramentos (Rojo, 2009, 2012; Santos e Rodrigues 2015, para citar apenas algumas), ainda há uma forte tendência da escola, leia-se, sobretudo do professor de LP, em conceber o trabalho de produção de textos como um mero exercício de codificação/decodificação.

Indo na mesma direção, a proposta de sequência didática (SCHNEUWLY e DOLZ, 2004) desenvolvida por M7, com 25 alunos da $1^{\text {a }}$ fase do $3^{\circ}$ ciclo de uma escola estadual, objetivou desenvolver habilidades de reflexão crítica, produção de texto de opinião e reescrita após a correção do professor, considerando a metodologia textual-interativa (RUIZ, 2015). 
Cuidadosamente, a mestranda elaborou a proposta e a implementou acreditando que os alunos melhorariam suas produções se fossem adequadamente orientados em que precisavam intervir em suas produções. Destarte, M7 ocupou-se de inúmeras interações, como o bilhete orientativo que segue:

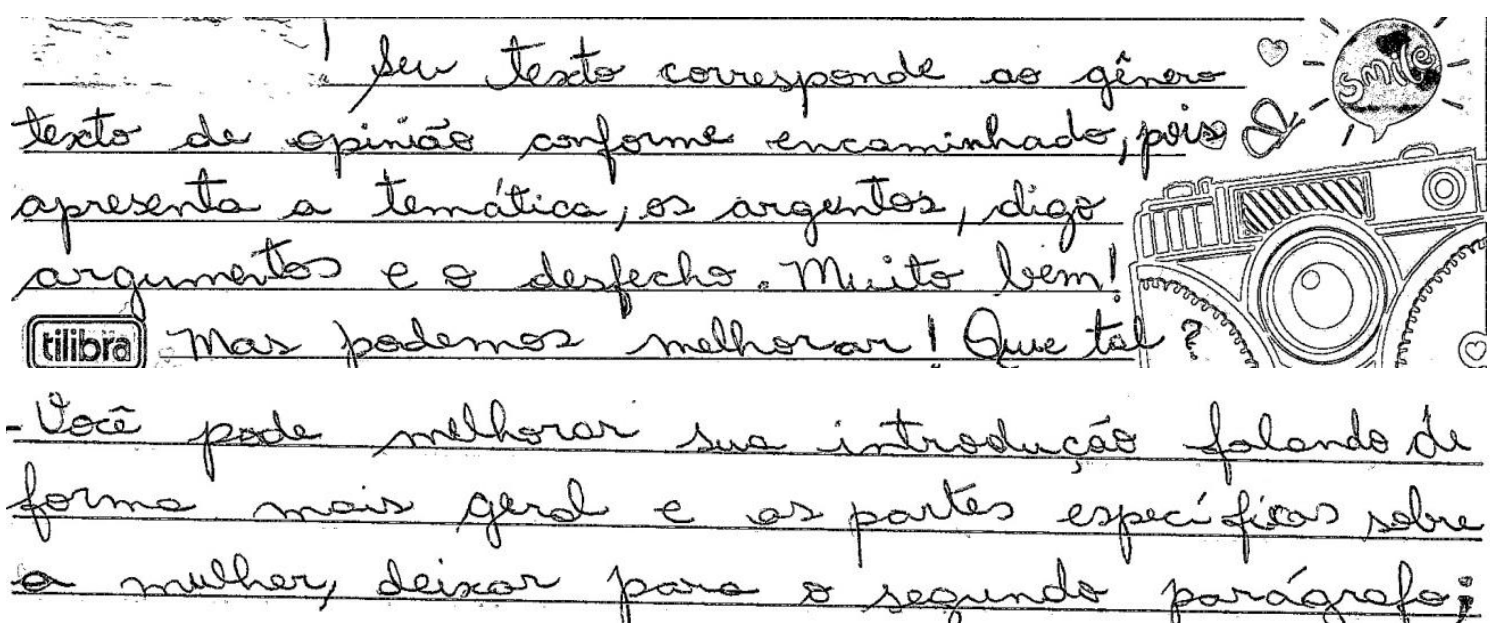

Fonte: Relato de experiência desenvolvida por M7 (2015, p. 10)

Ao refletir sobre sua prática, M7 argumenta que:

Os bilhetes orientadores aliados ao espaço para a reescrita abrem caminho para uma reflexão sobre o próprio texto e para a aprendizagem de práticas de escrita. Mesmo a tendência de "responder" as questões levantadas pelo bilhete no texto funcionou como um incentivo à elaboração e como estratégia para a apropriação do gênero. Além disso, as questões levantadas pelos bilhetes não poderiam ser abordadas através de estratégias tradicionais de correção, como a marcação dos problemas, correção dos mesmos ou atribuição de símbolos. (M7, 2015, p. 14)

Para ela, a experiência proposta na disciplina ASMLE lhe possibilitou o aperfeiçoamento do exercício de orientação mediadora, estimulando os alunos a verem a escrita/rescrita, como atos inseparáveis e necessários para a produção de texto com qualidade. Assevera, ainda, que a correção textual-interativa desenvolve a capacidade de reflexão, autonomia e melhoria na escrita e reescrita de textos dos alunos, além de propiciar maior interação entre estes e o professor.

O trabalho proposto por M8 objetivou analisar situações entre a prática docente e a qualidade da produção textual de alunos de um $9^{\circ}$ ano. A mestranda preocupou-se em evidenciar a importância do trabalho prévio em sala de aula, proporcionando-lhes atividades capazes de oportunizar aos educandos momentos de planejamento, produção-reflexão, revisão e reescrita textual. No decorrer da proposta, M8 analisou a evolução dos textos produzidos pelos alunos e as refacções textuais a partir da correção textual-interativa.

Ao desenvolver as atividades, a professora foi experienciando conceitos discutidos durante a disciplina ASMLE. No âmbito sociocognitivo, um deles, por exemplo, foi o "apagamento do conhecimento prévio" na realização da primeira produção, quer dizer, ela simplesmente solicitou a escrita de um texto. Alinhada ás teorias estudadas, já na segunda proposta, a professora proveu diferentes encaminhamentos para a produção textual do gênero artigo de opinião, bem como os encorajou a publicá-los no blog da escola, o que, notoriamente, culminou em uma escrita mais bem elaborada. Ela assim descreve os resultados: 
Ao comparar o primeiro texto com o segundo pode-se observar a evolução da produção textual deste jovem em relação a organização dos argumentos, o desenvolvimento da temática, a estrutura textual. Evolução esta que foi possibilitada a partir dos conhecimentos prévios adquiridos e o respeito as etapas que fazem parte do processo da produção textual. (M8, 2015, p. 11).

M8 optou pela estratégia de correção textual-interativa, em forma de bilhetes novidade tanto para os alunos quanto para a mestranda, pois, como descreve, "até então os textos eram corrigidos na própria folha, onde era grifado o que precisava ser alterado. Este tipo de correção é diferente, muito interessante e construtiva". (M8, 2015, p. 13).

Para M8, a estratégia de correção textual-interativa mostrou-se uma ótima opção metacognitva e sociocognitiva, promovendo interação entre os alunos e a professora. Ademais, promoveu ricos momentos de revisão de suas práticas docentes, conforme mostra o relato que segue:

Este trabalho proporcionou momentos de reflexão sobre minha prática como docente, pois para realizá-lo pesquisei sobre o assunto. Durante a leitura recordei da fala de colegas que afirmavam que os alunos tinham dificuldade em escrever, e percebi que esta fala também fazia parte do meu discurso, recordei de relatos dos próprios alunos que afirmavam que na hora de escrever acabavam se enrolando com as ideias e não escrevendo o que realmente queriam. A partir de então pensei em realizar um trabalho que mostrasse que a tarefa da escrita e reescrita poderia ajudá-los a superar estes obstáculos, principalmente se descobrisse onde estava falhando em minha prática, e que pudesse mudar o meu discurso e o discurso de alguns alunos. (M8, 2015, p. 3)

O quarto trabalho que contém o bloco de propostas de (re)escrita foi desenvolvido por M9, em que esmerou-se em experienciar a estratégia textual-interativa de correção proposta por Ruiz (2015) a partir de atividades de escrita e reescrita com 39 alunos de uma $7^{\text {a }}$ série. Ela verificou quais estratégias de correção utilizava e refletiu sobre o significado da prática docente e do incentivo à pesquisa.

Após analisar suas próprias práticas de correção, M9 evidenciou que em todos os textos havia "a presença da correção indicativa, com sublinhados e/ou círculos em volta de palavras ou expressões, seguida de um código abaixo do texto, característica da correção classificatória" e em alguns apareceram "tentativa de estabelecer um diálogo com os alunos, incentivando-os sobre seus acertos e para uma escrita mais eficaz” (M9, 2015, p. 11-12).

A reflexão desencadeada por M9 mostra ter se apropriado dos conceitos discutidos durante as aulas de ASMLE para realizar as intervenções nos direcionamentos para a refacção dos textos. Suas ponderações sinalizam, também, que os alunos não tinham costume de realizar o tipo de reescrita proposto, de forma que muitos não compreenderam e não realizaram as revisões necessárias. Ela defende que o professor precisa ter um papel de mediador do conhecimento e, no trabalho de reescrita "reconhece o êxito em escrever textos de qualidade, com uma postura de interesse e preocupação com o texto final, e não apenas corrige ou dá um visto geral no texto do aluno, indicando que "está bom", "regular" ou "ruim"”. (M9, 2015, p. 14).

Por fim, a mestranda reconhece a importância do experimento realizado

para a ampliação de meus conhecimentos sobre a temática da reescrita de textos e sobre o aperfeiçoamento de minhas práticas pedagógicas, a fim de que minha progressão na atuação profissional com as atividades de linguagens sejam condicionantes constantes na prática docente. (M9, 2015, p. 14). 
Completando as intervenções que formam o corpus em análise neste texto, o trabalho de produção textual proposto por M10 foi o desenvolvimento de uma sequência didática, nos moldes descritos por Dolz e Schneuwly (2004), com 21 alunos de um $9^{\circ}$ ano, em que optou por realizar três reescritas, envolvendo os três tipos de correções propostos por Ruiz (2015) na primeira, usou a indicativa; na segunda, a indicativa e a resolutiva; e, na terceira, a textualinterativa. A mestranda preocupou-se também em realizar uma entrevista com quatorze alunos para verificar a receptividade da proposta de refacção e a relação de uso que eles mantêm com a escrita.

M10 ajuíza que os alunos conseguiram realizar as correções indicativas, em nível ortográfico, mais facilmente que as demais, mas alerta para a função restritiva deste tipo de correção, já que, mesmo relendo o texto, os alunos não conseguem perceber equívocos de outra natureza, pois, em suas palavras, "o aluno pressupõe que todos os problemas que o seu texto apresenta já foram indicados pelo professor, logo o educando acredita que a sua única tarefa seja transcrever o seu texto e corrigir o que o professor apontou" (M10, 2015, p. 11).

Já na segunda reescrita, quando usou a correção indicativa e a resolutiva, cujo foco era instigá-los a perceberem a necessidade de organizar o texto para que fique mais coerente, M10 surpreendeu-se com os resultados demonstrados pelos alunos, uma vez que, modificaram "boa parte do texto, evidenciando a saída do mero processo de cópia e iniciando o processo de reflexão sobre o que escreveu. A maioria dos alunos conseguiu perceber a necessidade de modificar alguma coisa em sua produção textual”. (M10, 2015, p. 12).

Corroborando o pensamento de Ruiz (2015), os dados de M10 mostraram que a correção textual-interativa através de bilhetes pós-texto, permitiu o envolvimento do aluno como autor da sua produção e apresenta-se de forma mais autêntica.

percebemos que os alunos realizam uma produção textual dentro das suas limitações, o que os desmotiva a produzir em sala é a forma como as propostas de produção são apresentadas, não é o tema escolhido que é difícil, mas os alunos não se sentem motivados quando percebem que o seu texto não será lido nem pelo professor, situação que acontece na maioria das escolas brasileiras. (M10, 2015, p. 15).

Interessante observar a reflexão realizada por M10, em que assevera que os resultados demonstram a necessidade de um direcionamento do foco para um ensino pautado nas necessidades comunicativas reais dos alunos, promovendo um ensino de língua eficaz que valorize as múltiplas formas de escrita alimentadas na sociedade. (M10, 2015, p. 15).

\section{Finalizando}

Neste texto apresentei, brevemente, ponderações acerca da formação inicial e continuada de docentes da área de linguagens, sobretudo do professor de Língua Portuguesa. Apontei o PROFLETRAS como uma política de formação continuada stricto sensu em nível nacional e pontuei sobre a disciplina ASMLE desenvolvida na Unidade da UNEMAT/Sinop.

Na sequência tratei de questões voltadas ao ensino da leitura e da escrita, com enfoque em perspectiva (meta)cognitiva. Por fim, apresentei e analisei os trabalhos práticos desenvolvidos por dez mestrandos que participaram da disciplina em 2015 e como desencadearam processos reflexivos de interpelação com a teoria discutida em sala durante as aulas no Programa.

Os resultados mostram que as discussões teóricas e o desenvolvimento das propostas empoderaram os docentes para a realização de uma prática diferenciada em sala de aula mediante apropriação de diferentes técnicas e estratégias de leitura, bem como do uso efetivo do procedimento metodológico sequência didática. 
Os dados também me permitem dizer que houve a revelação da importância de se trabalhar a linguagem em uma perspectiva que considere os aspectos sociocognitivos, metacognitivos e culturais, levando-se em conta conceitos gerais e locais.

Espera-se que as ações desenvolvidas no âmbito do Programa possa gerar algum tipo de inovação. Com base no que vivi e ouvi no decorrer da disciplina, considero que o contato com teorias que discutem a (meta)cognição, a intervenção prática e os processos de reflexão da própria prática realizada, à luz das teorias estudadas, por si só, caracterizam-se, em certa medida, um tipo de inovação para o grupo envolvido.

A reflexão do fazer docente na perspectiva da pesquisa intervencionista mostrou-se altamente produtiva, em um ambiente colaborativo de discussão e apresentação de resultados, ao término da disciplina ASMLE. Fruto deste trabalho, houve o encorajamento para socializar as "descobertas" de forma glocal: apresentação e discussão em sala de aula durante a disciplina; socialização nas escolas de origem onde trabalham e desenvolveram as intervenções; socialização em eventos científicos (participação maciça da turma no VI Congresso Latino-Americano de Formação de Professores de Línguas, com apresentações de suas pesquisas interventivas).

E para mim, professora da disciplina, fica o sabor de poder participar de ricos momentos de socialização e ampla integração Universidade-Escola.

\section{Referências}

ABRUCIO, F. L. (Org.). Formação de professores no Brasil: diagnóstico, agenda de políticas e estratégias para a mudança. São Paulo: Moderna, 2016.

BAKHTIN, M./VOLOCHINOV, M. Marxismo e filosofia da linguagem. 6. ed. São Paulo: Hucitec, 1992.

BOLZAN, D. P. V.; ISAIA, S. M. A. Pedagogia universitária e aprendizagem docente: relações e novos sentidos da professoralidade. Revista Diálogo Educacional, Curitiba, v. 10, n. 29, p. 13-26, jan./abr. 2010. Disponível em: http://www.redalyc.org/articulo.oa?id=189114444002, acesso em 15 de setembro de 2016.

BORTONI-RICARDO, S, M; MACHADO, V. R; CASTANHEIRA, S. F. (Orgs.). Formação do professor como agente letrador. 2. reimpressão. São Paulo: Contexto, 2013.

BORTONI-RICARDO, S. M. O professor pesquisador: introdução à pesquisa qualitativa. São Paulo: Parábola Editorial, 2008.

BRASIL. Diretrizes Curriculares Nacionais para a formação inicial em nível superior. Ministério da Educação. Conselho Nacional de Educação. Resolução n. 02, de 01 de julho de 2015.

Parâmetros curriculares Nacionais. Secretaria de Educação Fundamental. Brasília: MEC/SEF, 1997.

CELANI, M. A. A. Um desafio na Linguística Aplicada contemporânea: a construção de saberes locais. D.E.L.T.A. v. 32. n. 2, 2016, p. 543-555.

DAVIS, Cláudia; NUNES, Marina M. R.; NUNES, Cesar A. A. Metacognição e sucesso escolar: articulando teoria e prática. Cadernos de Pesquisa, v. 35, n. 125, 2005, p. 205-230. 
DOLZ, J.; NOVERRAZ,; SCHNEUWLY, B. Sequências didáticas para o oral e a escrita: apresentação de um procedimento. In: SCHNEUWLY, B.; DOLZ, J. et al. Gêneros orais e escritos na escola. Trad. e org. de Roxane Rojo e Glaís Sales Cordeiro. Campinas, SP: Mercado de Letras, 2004. p. 95-128.

FERRAREZI JR., Celso; CARVALHO, Robson Santos de. Produzir textos na educação básica: o que saber, como fazer. São Paulo: Parábola Editorial, 2015.

FREITAS, James Deam Amaral. Aula de Língua Portuguesa - (re)descobrindo trajetos e desvios. Revista Brasileira de Linguística Aplicada, Belo Horizonte, v. 15, n. 4, 2016, p. 903-923.

GATTI, B. A. Análise das políticas públicas para formação continuada no Brasil, na última década. Revista Brasileira de Educação, v. 13, n. 37, jan./abr. 2008. p. 57-70.

GATTI, B, A. Formação de professores no Brasil: características e problemas. Educ. Soc. Campinas, v. 31, n. 113, p. 1355-1379, out./dez. 2010.

HAYES, J. R.; FLOWERS, L. S. Identifying the organization of writing process. In: GREGG, L. W.; STEINBERG, E. R. (Eds.). Cognitive processes in writing. New Jersey: Laurence Erlbaum, 1980.

JOU, G. I.; SPERB, T. M. A metacognição como estratégia reguladora da aprendizagem. Psicologia: reflexão e crítica, v. 19, n. 2, 2006.

KLEIMAN, A. B. Letramento e suas implicações para o ensino de língua materna. Signo. Santa Cruz do Sul, v. 32 n 53, p. 1-25, dez, 2007.

KLEIMAN, A. Professores e agentes de letramento: identidade e posicionamento social. Filologia e Linguística Portuguesa, v. 8, n. 2, p. 409-424, 2006.

KUMARAVADIVELU, B. A Linguística Aplicada na era da globalização. In: MOITA LOPES, L. P. da (Org.). Por uma Linguistica Aplicada INdisciplinar. São Paulo: Parábola Editorial, 2006.

LEFFA, V. J.; PEREIRA, A. E. O Ensino da leitura e produção textual. Pelotas, RS: Educat, 1999.

LEFFA, V. J. Aspectos da leitura: uma perspectiva psicolinguística. Porto Alegre: SAGRA - D.C Luzzatto Editores, 1996.

MEURER, J. L. Esboço de um modelo de produção de textos. In: MEURER, J. L.; MOTTAROTH, D. (Orgs.). Parâmetros de textualização. Santa Maria: Editora UFSM, 1997.

NATAL. Matriz curricular do Profletras. Universidade Federal do Rio Grande do Norte. Natal, RN, 2013.

BRAVIN, A; PAlOMANES, R. (Orgs.). Práticas de ensino de português. São Paulo: Contexto, 2013.

ROJO, R. Letramentos múltiplos, escola e inclusão social. São Paulo: Parábola, 2009. 
ROJO, R.; MOURA, E. (Orgs.). Multiletramentos na escola. São Paulo: Parábola, 2012.

RUIZ, E. D. Como corrigir redações na escola: uma proposta textual-interativa. 1. ed., 3. reimpressão. São Paulo: Contexto, 2015.

SANTOS, L. I. S.; RODRIGUES, G. R. Multiletramentos: articulações para/no ensino da leitura e da escrita. Cáceres, MT: Editora UNEMAT, 2015.

SANTOS, L. I. S.; SANTOS, L. A. Formação docente e ensino de língua portuguesa. Signótica, 2016 (no prelo).

SARTORI, Adriane T. Ensino de Língua Portuguesa: reflexões sobre a necessidade de análise crítica de textos. Revista Brasileira de Linguística Aplicada, Belo Horizonte, v. 15, n. 4, 2016, p. 925-940.

SCHNEUWLY, B.; DOLZ, J. Os Gêneros Escolares - Das Práticas de Linguagem aos Objetos de Ensino. In: SCHNEUWLY, B.; DOLZ, J. et al. Gêneros orais e escritos na escola. Campinas: Mercado de Letras, 2004. p. 95-128.

SILVA, K. A.; MASTREllA-DE-ANDRADE, M.; PEREIRA FILHO, C. A. (Orgs.). A formação de professores de línguas: políticas, projetos e parcerias. Campinas, SP: Pontes Editores, 2015.

SIQUEIRA, S. Diversidade, ensino e linguagem: que desafios e compromissos aguardam o profissional de Letras contemporâneo? Revista Línguas \& Letras, v. 13, n. 24, $1^{\circ}$ Sem. 2012, p. 35-66.

SOLÉ, Isabel. Estratégias de leitura. 6. ed. Porto Alegre: Artmed, 1998. 
